\title{
PENGARUH REKRUTMEN DAN SELEKSI TERHADAP KINERJA
}

\author{
Tengku Ariefanda Aziz ${ }^{* 1}$, M. Syamsul Maarif ${ }^{*}$, dan Anggraini Sukmawati**) \\ *) Sekolah Bisnis, Institut Pertanian Bogor \\ Gedung SB IPB - Jl. Raya Pajajaran, Bogor 16151 \\ **) Departemen Manajemen, Fakultas Ekonomi dan Manajemen, Institut Pertanian Bogor \\ Jl. Agatis Kampus IPB Darmaga, Bogor 16680
}

\begin{abstract}
The aims of this study were to clarify the impact of recruitment on selection, impact of the recruitment and on performance, and impact of selection on the employee performance at INALUM. The approach used in this research was descriptive, and data were processed by using Structural Equation Modeling (SEM) technique. There were 105 samples in this study coming from the company. These results indicate that the recruitment has an impact on selection, selection affects the performance, and recruitment directly influences the performance. In this case, the company can increase the variables that need to be corrected in the future
\end{abstract}

Keywords: recruitment, selection and performace, SEM, Inalum

\begin{abstract}
ABSTRAK
Tujuan dari penelitian ini adalah untuk menjelaskan apakah pengaruh dari perekrutan terhadap seleksi, pengaruh rekrutmen terhadap kinerja, dan pengaruh seleksi terhadap kinerja karyawan. Pendekatan yang telah digunakan dalam penelitian ini adalah deskriptif dan pengolahan data dengan menggunakan Structural Equation Modeling (SEM) Teknik. Sampel dari penelitian ini adalah 105 karyawan. Hasil penelitian ini menunjukkan bahwa rekrutmen berpengaruh terhadap seleksi. seleksi berpengaruh terhadap kinerja dan rekrutmen secara langsung berpengaruh oleh kinerja. Dalam hal ini perusahaan dapat meningkatkan variabel-variabel yang perlu diperbaiki di masa yang akan datang
\end{abstract}

Kata kunci: rekrutmen, seleksi, kinerja, SEM, Inalum

\footnotetext{
${ }^{1}$ Alamat Korespondensi:

Email: langkat0705@gmail.com
}

\section{PENDAHULUAN}

Manajemen sumber daya manusia (SDM) haruslah terdiri dari aktivitas-aktivitas yang terkait dengan manajemen SDM meliputi: perencanaan dan analisis SDM, kesetaraan kesempatan bekerja, perekrutan pengembangan SDM, kompensasi dan keuntungan, kesehatan, keselamatan dan keamanan. Salah satunya adalah rekrutmen menurut Ullman (1966), teknik perekrutan dapat diidentifikasi sebagai baik formal maupun informal. Dalam literatur, teknik perekrutan seperti iklan koran, pusat kerja dan agen tenaga kerja dianggap sebagai resmi sedangkan teknik seperti "dari mulut ke mulut" oleh karyawan yang ada, juga dikenal sebagai "arahan" adalah contoh dari teknik perekrutan tidak resmi (Taylor, 1994). Simamora (2006) menjabarkan beberapa poin penting yang harus diperhatikan dalam melakukan rekrutmen antara lain: penyusunan strategi untuk merekrut, pencarian pelamar-pelamar kerja, penyisihan pelamar-pelamar yang tidak cocok/penyaringan, pembuatan kumpulan pelamar. Dalam proses rekrutmen yang dilakukan oleh perusahaan juga terdapat banyak aspek lainnya yang menjadi pertimbangan dalam calon karyawan untuk berkomitmen dengan tahapan rekrutmen yang dilakukan oleh perusahaan.

Menurut Wibowo (2007), kinerja merupakan hasil pekerjaan yang mempunyai hubungan kuat dengan tujuan strategis organisasi. Lingkungan tersebut meliputi banyak faktor globalisasi berkembang, perubahan teknologi yang cepat, dan kebutuhan yang berkembang untuk karyawan dan peningkatan kinerja (Vanhala dan Stavrou, 2013). Mengelola kinerja telah 
menjadi subyek perdebatan tentang nilai kinerja, pengukuran dan manajemen, dan juga menjadi area pertumbuhan dalam administrasi dan manajemen publik (Van de Walle, 2009; Talbot, 2010). Sangeetha (2010) mendefinisikan rekrutment sebagai proses identifikasi dan perekrutan kandidat terbaik dan berkualitas tinggi (dari dalam maupun luar organisasi) pada waktu yang tepat dan biaya yang efektif.

Menurut Vroom (1964) menunjukkan bahwa kinerja berbanding lurus dengan motivasi dan kemampuan. Preview pekerjaan yang realistis dan penilaian bermain peran yang rekrutmen dan seleksi teknik yang dapat digunakan untuk meningkatkan keterlibatan dengan menyelaraskan harapan calon dengan harapan organisasi. Rekrutmen merupakan suatu kegiatan untuk mencari sebanyak- banyaknya calon tenaga kerja sesuai lowongan yang tersedia sumber-sumber yang dimana terdapatnya calon pekerja tersebut diperoleh dari Departemen Tenaga Kerja dan lembaga pendidikan, biro konsultan iklan media massa dan tenaga kerja organisasi sendiri (Umar, 2005).

Rao (2010) telah mengidentifikasi rekrutmen internal karyawan referensi, perencanaan suksesi, wawancara, tes kepribadian, perekrutan koran, lembaga pencari profesional, dan biodata sebagai praktek kepegawaian tingkat senior dominan. Parry dan Tyson (2008) telah meneliti bahwa secara online metode perekrutan lebih cocok untuk pengetahuan pekerja dan manajemen menengah dan kurang tepat untuk pekerjaan kerah biru atau sangat manajemen tingkat tinggi.Tampaknya penggunaan metode rekrutmen online tetap lebih lazim di organisasi pelayanan. Namun, dalam prakteknya, hal ini tidak sesederhana kedengarannya (O'Leary et al. 2002). Rekrutmen adalah masalah penting dalam pengadaan tenaga kerja (Odoguwu, 2012). Newell dan Rice (1999) mencatat bahwa untuk beberapa, rekrutmen/seleksi terletak di pusat sangat praktek sumber daya manusia dalam organisasi dimana keputusan pengangkatan merupakan salah satu yang paling penting yang pernah diambil oleh majikan.

Tujuan dari penulisan ini adalah untuk mengetahui pengaruh rekrutment terhadap seleksi pada PT INALUM, mengetahui pengaruh seleksi terhadap kinerja pada PT INALUM dan mengetahui pengaruh rekrutment terhadap kinerja pada PT INALUM. Penelitian yang dilakukan terkait dengan topik tersebut, diharapkan akan dapat memberikan manfaat, yaitu bagi PT INALUM, diharapkan dapat memberikan analisa dan rekomendasi manajerial terkait dengan pelaksanaan pola rekrutmen yang baik dalam upaya meningkatkan kinerja karyawan PT INALUM dan bagi pembaca, diharapkan dapat meningkatkan wawasan terkait dengan hasil penelitian. Sehubungan dengan itu, penelitian sebelumnya (Yulianti, 2009) ketiga variabel (rekrutmen, seleksi dan kinerja) tidak saling memengaruhi sedangkan dalam karya ilmiah ini ketiga faktor tersebut saling berpengaruh. Mengelola kinerja telah menjadi subyek perdebatan tentang nilai kinerja, pengukuran dan manajemen, dan juga menjadi area pertumbuhan dalam administrasi dan manajemen publik (Van de Walle, 2009; Talbot, 2010). Penilaian kinerja menjadi dasar untuk keputusan organisasi tertentu seperti menentukan gaji paket dan promosi (Sripirabaa dan Krishnaveni, 2009)

Penelitian ini akan difokuskan pada analisa bidang sumber daya manusia. Khususnya pola rekrutmen dan seleksi terhadap kinerja karyawan PT INALUM. Ruang lingkup penelitian ini meliputi rekrutmen dan seleksi terhadap kinerja beserta variabel masingmasing didalamnya. Penelitian ini untuk menganalisis hubungan tiga variabel yang diteliti. Diharapkan dengan adanya penelitian ini mendapat penjelasan pola rekrutmen dan seleksi terhadap kinerja di PT INALUM.

\section{METODE PENELITIAN}

Penelitian ini dilakukan di PT INALUM yang berlokasi di Kantor Pusat PT INALUM, di Sumatera Utara dari bulan Juli 2014 sampai dengan September 2014. PT Indonesia Asahan Aluminium (INALUM) merupakan sebuah perusahaan patungan antara pemerintah Indonesia dan Nippon Asahan Aluminium Co., Ltd, PT INALUM adalah perusahaan yang membangun dan mengoperasikan proyek Asahan, sesuai dengan perjanjian Induk. PT INALUM yang berpusat di Sumatera Utara, Kuala Tanjung juga memiliki unitunit yang terdapat di beberapa wilayah Indonesia, yaitu Jakarta dan Medan sebagai pusat bisnis dan Paritohan.

Data yang digunakan dalam penelitian ini bersumber dari dua jenis data, yaitu data primer dan data sekunder. Pengambilan data sekunder didapatkan dari annual report, PT INALUM, internet, buku referensi dan dokumen pendukung lainnya yang relevan. Teknik pengumpulan dengan menggunakan kuesioner. dengan melakukan wawancara pada Human Resources 
Departement (manajer, person in charge terkait) dan Board of Director. Desain penelitian yang diterapkan adalah dengan metode deskriptif dalam bentuk intepretasi hasil pengambilan dan pengolahan data (wawancara langsung dan kuesioner). Menurut Soejono (2005) pendekatan deskriptif adalah pendekatan untuk melihat keadaan suatu individu, gejala atau kelompok tertentu. Sementara itu, untuk pengambilan data primer melalui kuesioner dilakukan dengan membagikan kuesioner pada karyawan tetap (berstatus aktif bekerja sampai dengan waktu penelitian dilakukan). Pemilihan responden dilakukan dengan menggunakan teknik proportional stratified random sampling sesuai dengan komposisi jumlah karyawan pada masing-masing bagian PT INALUM yang berjumlah 1.911 orang. Namun, karena menggunakan model analisis Structural Equation Modeling (SEM), penelitian ini menggunakan 106 orang sebagai sampel menggunakan teknik maksimum yang diamati terhadap variabel. Indikator ini dilakukan penelitian dijelaskan pada Tabel 1 .
Sesuai dengan kajian utama dalam penelitian ini adalah untuk mengetahui hubungan antara pola rekrutmen dan seleksi karyawan terhadap kinerja karyawan PT INALUM maka dalam penelitian ini akan dilakukan penelitian pada tiga variabel utama, yaitu pola rekrutmen karyawan, seleksi, dan kinerja karyawan PT INALUM.

Hubungan antara variabel bebas dan variabel terikat dianalisis dengan SEM. Didalam karakteristik SEM terdapat tiga komponen model SEM yang terdiri dari:

1. Jenis varibel, yaitu varibel laten (latent variabel) dan variabel teramati (observed atau measured atau manifest variabel)

2. Jenis model, yaitu model struktural (structural error) dan model pengukuran (measurement model)

3. Jenis kesalahan, yaitu kesalahan struktural (structural error) dan kesalahan pengukuran (measurement error)

Tabel 1. Hubungan variabel, dimensi dan indikator

\begin{tabular}{|c|c|c|c|}
\hline Variabel & & indikator variabel & Kode \\
\hline \multirow[t]{7}{*}{ Rekrutmen (R) } & 1 & Kebijakan organisasi & $\mathrm{X} 1$ \\
\hline & 2 & Perencanaan rekrutmen & $\mathrm{X} 2$ \\
\hline & 3 & Metode rekrutmen & $\mathrm{X} 3$ \\
\hline & 4 & Prosedur & $\mathrm{X} 4$ \\
\hline & 5 & Waktu pelaksanaan & $\mathrm{X} 5$ \\
\hline & 6 & Sumber-sumber rekrutmen & X6 \\
\hline & 7 & Kendala rekrutmen & $\mathrm{X} 7$ \\
\hline \multirow[t]{13}{*}{ Seleksi (S) } & 8 & Kebijakan seleksi perusahaan & Y8 \\
\hline & 9 & Metode seleksi & Y9 \\
\hline & 10 & Prosedur seleksi & Y10 \\
\hline & 11 & Pelaku seleksi & Y11 \\
\hline & 12 & Peserta seleksi & Y12 \\
\hline & 13 & Deskripsi pekerjaan & Y13 \\
\hline & 14 & Spesifikasi pekerjaan & Y14 \\
\hline & 15 & Sarana dan prasarana seleksi & Y15 \\
\hline & 16 & Kendala seleksi & Y16 \\
\hline & 17 & Pengetahuan atau pekerjaan & Y17 \\
\hline & 18 & Perencanaan dan organisasi & Y18 \\
\hline & 19 & Mutu pekerjaan, ketelitian & Y19 \\
\hline & 20 & Produktivitas & Y20 \\
\hline \multirow[t]{7}{*}{ Kinerja (K) } & 21 & Judgement naluri dan kebijakan & Y21 \\
\hline & 22 & Komunikasi dan hubungan & Y22 \\
\hline & 23 & Kerja sama & Y23 \\
\hline & 24 & Kehadiran & Y24 \\
\hline & 25 & Manajemen pekerjaan & Y25 \\
\hline & 26 & Kepemimpinan & Y26 \\
\hline & 27 & Kemampuan memperbaiki diri & Y27 \\
\hline
\end{tabular}


Adapun beberapa langkah yang perlu dilakukan untuk membuat permodelan yang lengkap, yaitu pengembangan model berbasis konsep dan teori, pengembangan diagram alur (path diagram), konversi diagram alur ke dalam persamaan struktural, memilih matriks input dan estimasi model, menilai masalah identifikasi, evaluasi model, serta interpretasi dan modifikasi model. Selanjutnya, kerangka pemikiran penelitian selengkapnya pada Gambar 1.

Dalam pengujian variabel tersebut, digunakan hipotesis penelitian sebagai berikut:

1. Ho : Tidak terdapat pengaruh positif dan signifikan rekrutmen terhadap seleksi pegawai di PT INALUM

$\mathrm{Ha}$ : Terdapat pengaruh positif dan signifikan rekrutmen terhadap seleksi pegawai di PT INALUM

2. Ho : Tidak terdapat pengaruh positif dan signifikan seleksi terhadap kinerja pegawai di PT INALUM

$\mathrm{Ha}$ : Terdapat pengaruh positif dan signifikan seleksi terhadap kinerja pegawai di PT INALUM
3. Ho : Tidak terdapat pengaruh positif dan signifikan rekrutmen terhadap kinerja pegawai di PT INALUM

$\mathrm{Ha}$ : Terdapat pengaruh positif dan signifikan rekrutmen terhadap kinerja pegawai di PT INALUM

\section{HASIL}

\section{Pengujian Hipotesis}

Dari hasil perhitungan melalui analisis faktor konfirmatori dan SEM maka model dalam penelitian ini dapat diterima. Berdasarkan Gambar 2, hasil telah memenuhi criteria GOF; chi square $=422,33$; probabilitas $=0,360 ; \quad \mathrm{CMIN} / \mathrm{DF}=321 ; \mathrm{GFI}=0,77$; $\mathrm{TLI}=0,993 ; \mathrm{CFI}=0,97 ; \mathrm{RMSEA}=0,055$. Selanjutnya berdasarkan model fit ini akan dilakukan pengujian kepada tiga hipotesis yang diajukan dalam penelitian. Pengujian GOF dilakukan untuk mengetahui seberapa fit model dengan data penelitian yang diperoleh, berikut ini adalah output gambar path diagram yang dihasilkan setelah melakukan tahapan pemenuhan uji asumsi path.

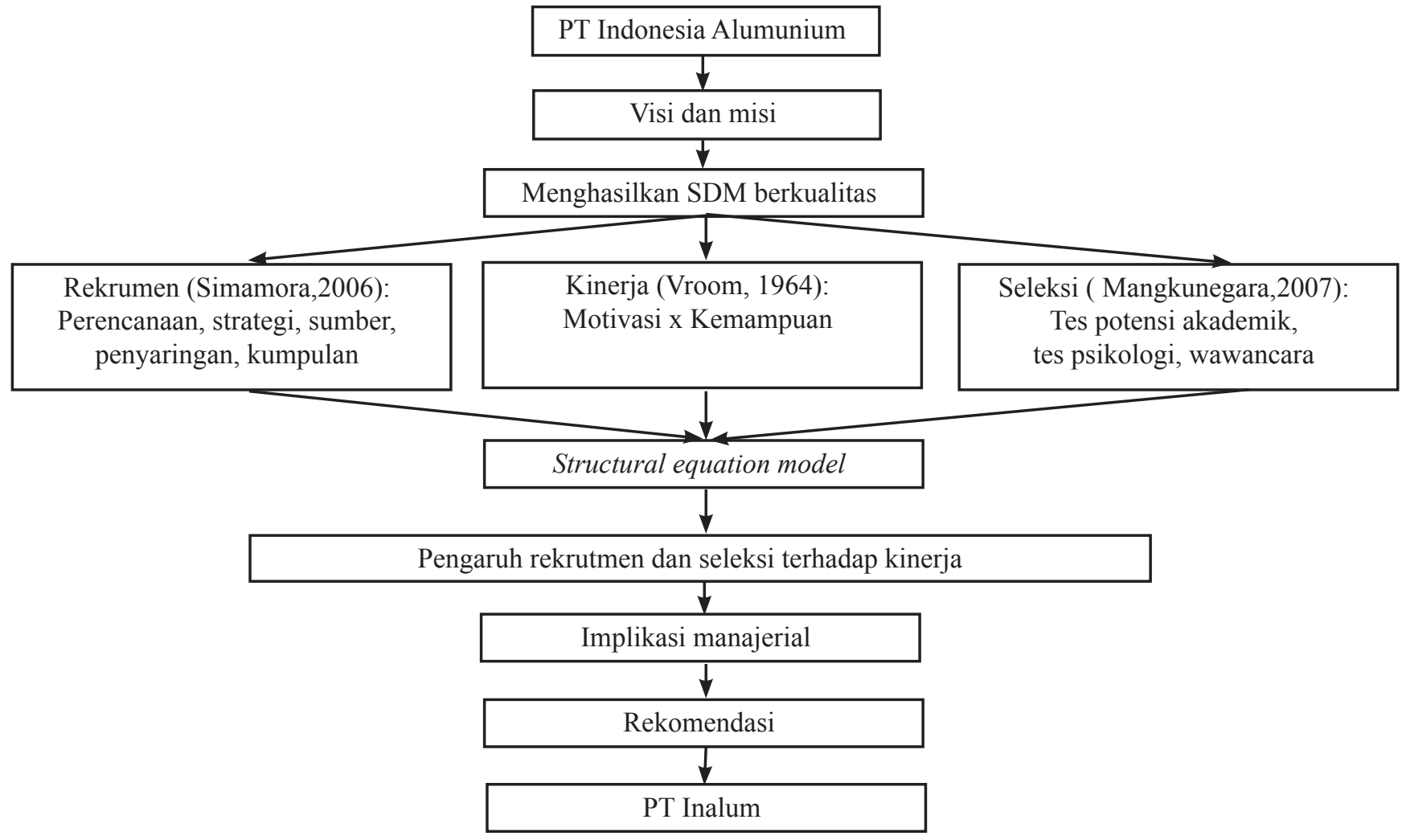

Gambar 1. Kerangka pemikiran penelitian 


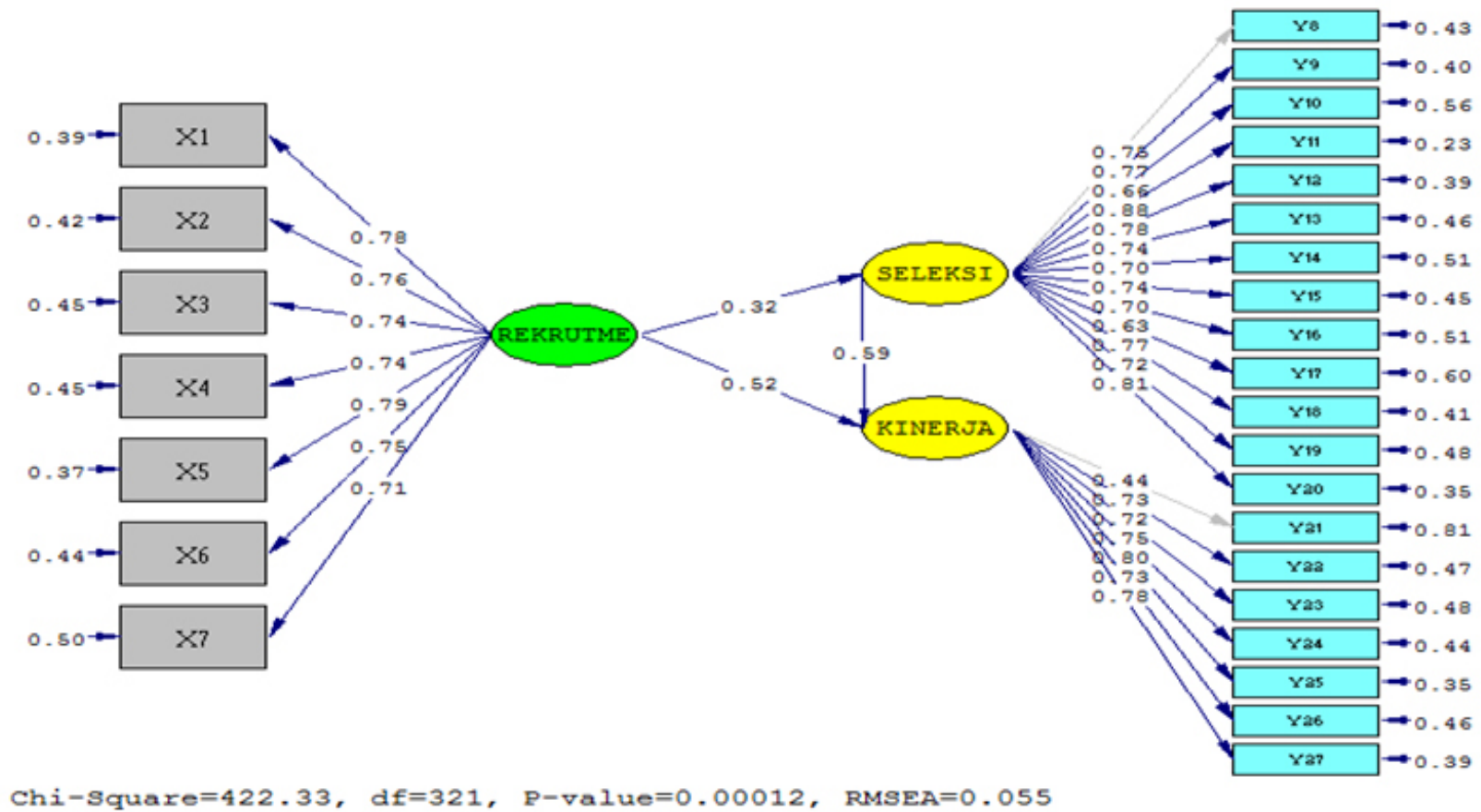

Gambar 2. Hasil pengujian model

\section{Hipotesis Rekrutmen terhadap Seleksi}

Evaluasi dilakukan dengan statistik uji t dengan standar $t$ tabel minimal 1,96. Berdasarkan Gambar 3 didapatkan bahwa variabel laten eksogen pertama, Rekrutmen memiliki nilai uji t 2,90 yang artinya Rekrutmen berpengaruh terhadap Seleksi. Semakin tinggi Rekrutmen yang dirasakan oleh karyawan maka akan membuat Seleksi Semakin tinggi. Hal ini sesuai dengan penelitian Pambagyo dan Utami (2013).

\section{Hipotesis:}

H0: variabel rekrutmen tidak berpengaruh signifikan terhadap variabel seleksi

$\mathrm{H} 1$ : variabel rekrutmen berpengaruh signifikan terhadap variabel seleksi

Dasar Pengambilan Keputusan, yaitu apabila probabilitasnya (nilai prob) $>0,05$ atau $-\mathrm{t}$ tabel $<\mathrm{t}$ hitung $<\mathrm{t}$ tabel maka H0 tidak ditolak. Selanjutnya, jika probabilitasnya (nilai prob) $<0,05$ atau $t$ hitung $<$ - $\mathrm{t}$ tabel atau $\mathrm{t}$ hitung $>\mathrm{t}$ tabel maka $\mathrm{H} 0$ ditolak ( $\mathrm{t}$ tabel untuk alfa $=0,05$ adalah 1,96 dan $\mathrm{t}$ tabel untuk alfa $=$ $0,10$ adalah 1,65$)$

\section{Hipotesis Seleksi terhadap Kinerja}

Pada Gambar 3 nilai t stat $=4,01>1,96$ sehingga H0 ditolak, yang berarti variabel Seleksi berpengaruh signifikan terhadap variabel Kinerja. artinya seleksi berpengaruh terhadap kinerja.

\section{Hipotesis:}

H0: variabel seleksi tidak berpengaruh signifikan terhadap variabel kinerja

H1: variabel seleksi berpengaruh signifikan terhadap variabel kinerja

Dasar Pengambilan Keputusan, yaitu apabila probabilitasnya (nilai prob) $>0,05$ atau $-\mathrm{t}$ tabel $<\mathrm{t}$ hitung $<\mathrm{t}$ tabel maka H0 tidak ditolak. Selain itu, jika probabilitasnya (nilai prob) $<0,05$ atau $\mathrm{t}$ hitung $<-\mathrm{t}$ tabel atau $\mathrm{t}$ hitung $>\mathrm{t}$ tabel maka $\mathrm{H} 0$ ditolak ( $\mathrm{t}$ tabel untuk alfa $=0,05$ adalah 1.96 dan $\mathrm{t}$ tabel untuk alfa $=$ 0.10 adalah 1,65$)$.

\section{Hipotesis Rekrutmen terhadap Kinerja}

Berdasarkan hipotesis Gambar 3 nilai t stat $=4,00$ $>$ 1,96 sehingga $\mathrm{H} 0$ ditolak, yang berarti variabel rekrutmen berpengaruh signifikan terhadap variabel kinerja. Makin tinggi rekrutmen, makin tinggi seleksi. Demikian juga sebaliknya. Hal ini diperkuat oleh penelitian Ivancevich (2001) dan Yulianti (2009) menyatakan bahwa Rekrutmen berkorelasi langsung dengan kinerja. 
Hipotesis:

H0: variabel rekrutmen tidak berpengaruh signifikan terhadap variabel kinerja

H1: variabel rekrutmen berpengaruh signifikan terhadap variabel kinerja

Dasar pengambilan keputusan ditentukan jika probabilitasnya (nilai prob) $>0,05$ atau $-\mathrm{t}$ tabel $<\mathrm{t}$ hitung $<\mathrm{t}$ tabel maka $\mathrm{H} 0$ tidak ditolak. Di samping itu, jika probabilitasnya (nilai prob) $<0,05$ atau $t$ hitung $<$ - $\mathrm{t}$ tabel atau $\mathrm{t}$ hitung $>\mathrm{t}$ tabel maka $\mathrm{H} 0$ ditolak ( $\mathrm{t}$ tabel untuk alfa $=0,05$ adalah 1,96 dan $\mathrm{t}$ tabel untuk alfa $=$ $0,10$ adalah 1,65$)$.

\section{Hubungan rekrutmen dengan Indikasi pembentuknya}

Dari hasil uji t tabel (Tabel 2) menunjukan bahwa ketiga variabel diatas waktu pelaksanaan (X5), kebijakan organisasi (X1) dan perencanaan rekrutmen (X2) lebih besar daripada $t$ tabel 1,96 signifikan terhadap variabel laten lain. Dari hasil uji, waktu pelaksanaan merupakan indikator yang tinggi karena merupakan standar perusahaan. Kedua, kebijakan organisasi menempati urutan yang kedua. Serta perencanaan rekrutmen menempati urutan yang ketiga berdasarkan hasil SEM. Ini menunjukkan bahwa standar yang ditetapkan oleh perusahaan sudah sejalan.

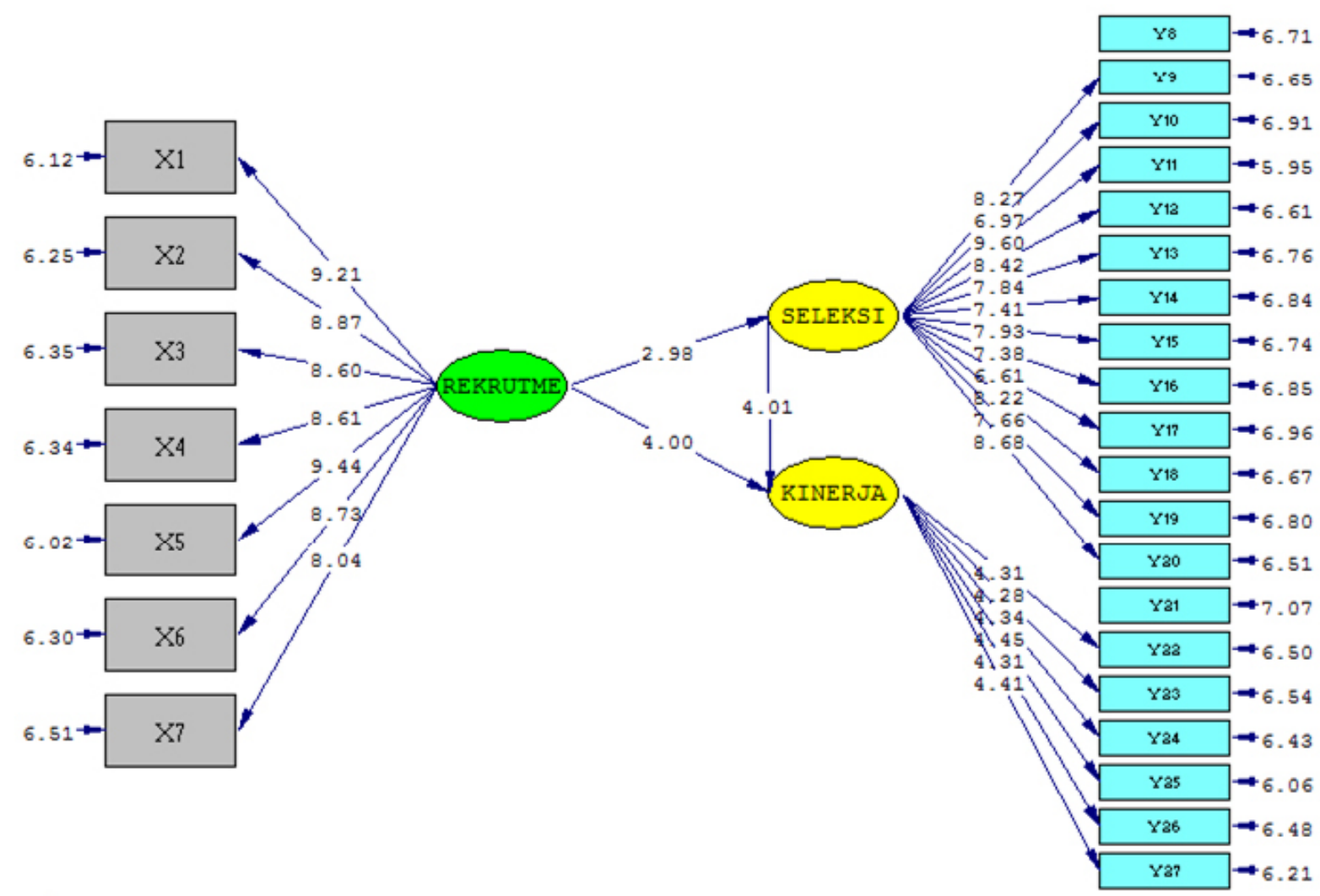

Chi-Square $=422.33, d f=321, \mathrm{p}-\mathrm{value}=0.00012, \mathrm{RMSEA}=0.055$

Gambar 3. Diagram path rekrutmen dan seleksi terhadap kinerja

Tabel 2. Hubungan rekrutmen dengan indikasi pembentuknya

\begin{tabular}{clccc}
\hline Variabel Laten & \multicolumn{1}{c}{ Dimensi } & Koefisien/ SLF $(\lambda)$ & T-value $(\geq 1,96)$ & Kesimpulan \\
\hline \multirow{3}{*}{ Rekrutmen } & Waktu pelaksanaan & 0,79 & 9,44 & Signifikan \\
& Kebijakan organisasi & 0,78 & 9,21 & Signifikan \\
& Perencanaan rekrutmen & 0,76 & 8,87 & Signifikan \\
\hline
\end{tabular}




\section{Hubungan seleksi dengan indikator pembentuknya}

Dari hasil indikator pada Tabel 3 ketiga dimensi, yaitu pelaku seleksi (Y11), produktivitas (Y20) dan peserta seleksi (Y12) mempunyai bobot yang lebih besar dari t-value lebih besar 1,96 (Tabel 4). Dari hasil ini pelaku seleksi menempatkan urutan pertama, karena responden melihat departemen SDM mempunyai peran yang penting dalam tujuan perusahaan. Produktivitas dalam melakukan seleksi diperingkat kedua karena proses seleksi variabel produktivitas menurut responden sesuai dengan tujuan perusahaan. Ketiga, peserta seleksi merupakan indikator penting oleh responden karena menunjukkan gambaran kebutuhan perusahaan apakah sesuai dengan tujuan perusahaan

\section{Hubungan kinerja dengan faktor pembentuknya}

Dari hubungan indikator yang terlihat di Tabel 4 ada tiga bobot yang lebih besar, yaitu manajemen pekerjaan (Y25), kemampuan memperbaiki diri (Y27), dan kehadiran (Y24) memiliki bobot t-value lebih besar dari 1,96 terhadap variabel latennya. Dari hasil uji, manajemen pekerjaan mempunyai bobot tertinggi. Kemampuan memperbaiki diri termasuk hal yang diperhatikan oleh karyawan. Kehadiran merupakan faktor yang terpenting karena perusahaan menerapkan disiplin dan target pekerjaan.

\section{Implikasi Manajerial}

Setelah melakukan pengujian pada terhadap beberapa variabel dalam selang ukuran, yaitu rekrutmen, seleksi, dan kinerja maka implikasi manajerial antara lain: pembenahan terhadap metode rekrutmen yang ada dan prosedur yang ada sangat diperlukan dilakukan bagian HRD agar dapat menjaring tenaga SDM yang memiliki kompetensi sesuai yang di harapkan. Pada proses seleksi dilakukan terhadap pola rekrutmen yang ada, terdapat beberapa hal yang harus dilakukan oleh PT Inalum, yaitu pelaku seleksi, pengetahuan pekerjaan, mutu pekerjaan harus memenuhi kebutuhan perusahaan kedepan dalam komunikasi maupun merekrut karyawan profesional. Dimensi kinerja perlu diperbaiki judgement naluri dan kebijakan menyelesaikan masalah komunikasi dan kerja sama perlu gagasan dari manajemen untuk training agar karyawan berkembang.

\section{KESIMPULAN DAN SARAN}

\section{Kesimpulan}

Hasil penelitian menunjukan bahwa ketiga variabel dari faktor rekrutmen dan seleksi mempunyai hubungan yang positif akan tetapi mempunyai indikator indikator yang perlu diperbaiki. Seperti metode rekrutmen, prosedur dan kendala rekrutmen. Indikator pertama adalah rekrutmen diatas waktu pelaksanaan, kebijakan organisasi dan perencanaan rekrutmen mempunyai muatan faktor yang besar. Begitu juga seleksi terhadap kinerja mempunyai hubungan yang positif indikator pendukungnya adalah pelaku seleksi, produktivitas dan peserta seleksi, dan rekrutmen terhadap kinerja mempunyai hubungan positif indikator kinerja, yaitu manajemenpekerjaan,kemampuanmemperbaikidiridan kehadiran. Adapun yang menjadi kesimpulan rekrutmen dan seleksi perusahaan harus memperbaharui sistem perekrutan. baik level staf maupun level manajerial dengan memperbaharui sistem perusahaan mempunyai daya saing lebih baik. Dengan mengupdate kebutuhan dan pengetahuan karyawan dapat bekerja maksimal. hal ini memberikan kontribusi besar terhadap kinerja karyawan. Sistem perekrutan hendaknya mengacu kepada daya saing dengan begitu perusahaan mampu mewujudkan tujuan perusahaan. Sistem rekrutmen di manufaktur mengacu pada keahlian pekerja dan mampu beradaptasi dengan perkembangan jaman.

Tabel 3. Hubungan seleksi dengan indikator pembentuknya

\begin{tabular}{clccc}
\hline Variabel laten & \multicolumn{1}{c}{ Dimensi } & Koefisien/ SLF $(\lambda)$ & T-value $(\geq 1,96)$ & Kesimpulan \\
\hline \multirow{3}{*}{ Seleksi } & Pelaku seleksi & 0,88 & 8,40 & Signifikan \\
& Produktivitas & 0,81 & 8,63 & Signifikan \\
& Peserta seleksi & 0,79 & 7,84 & Signifikan \\
\hline
\end{tabular}

Tabel 4. Hubungan kinerja dengan variabel pembentuknya

\begin{tabular}{clccc}
\hline Variabel laten & \multicolumn{1}{c}{ Dimensi } & Koefisien/ SLF $(\lambda)$ & T-value $(\geq 1,96)$ & Kesimpulan \\
\hline \multirow{3}{*}{ Kinerja } & Manajemen pekerjaan & 0,81 & 7,37 & Signifikan \\
& Kemampuan memperbaiki diri & 0,79 & 7,92 & Signifikan \\
& Kehadiran & 0,75 & 8,14 & Signifikan \\
\hline
\end{tabular}




\section{Saran}

Dari hasil penelitian ini maka PT INALUM harus memperhatikan bebrapa hal untuk mencapai tujuan perusahaan antara lain: pelatihan karyawan mutlak diperlukan agar kerja sama maupun komunikasi yang baik tercapai dan menjaga kekompakan. Perusahaan hendaknya merekrut tenaga terampil agar menjadi sinergi antara karyawan berpengalaman maupun tidak.

\section{DAFTAR PUSTAKA}

Newell S, Rice C. 1999. Assessment, selection and evaluation: problems and pitfalls, in Millmore, M. (Eds.), just how extensive is the practice of strategic recruitment and selection? The Irish Journal of Management (1)8: 1-6.

Ivancevich, John M. 2001. Human Resource Management. New York: Mc. Grow - Hill Companies

Odoguwu C. 2012. Recruitment practices and performance of unionised organisations in the food, beverage and tobacco industry in Lagos State. Nigeria Interdiscipline Journal of Contemporary Resourches In Business 5:47534754.

O'Leary B, Lou Lindholm M, Whitford R, Freeman S. 2002. Selecting the best and the brightest: Leveraging human capital. Human Resource Management 41(3):325-340. http://dx.doi. org/10.1002/hrm.10044

PT INALUM. 2013. Jumlah karyawan PT. INALUM per 31 Oktober 2012. http://www.INALUM.co.id/ ind/index.php/tentang INALUM/karyawan.html [diakses 20 Oktober 2013]

Pambagyo NS, Utami HN. 2013. Pengaruh proses rekrutmen, proses seleksi kompentensi karyawan terhadap kinerja karyawan Malang [tesis]. Malang: Universitas Brawijaya.

Parry E, Tyson S. 2008. An analysis of the use and success of online recruitment methods in the UK. Human Resource Management Journal 18(3): 25-74.
Rao P. 2010. A resource-based analysis of recruitment and selection practices of indian software companies, a case study approach. Journal of Indian Business Research 2(1):32-51.

Sangeetha K. 2010. Effective recruitment: a framework. The IUP Journal of Business Strategy 2(1\&2).

Simamora H. 2006. Manajemen Sumber Daya Manusia 3. Yogyakarta: STIE YKPN.

Soejono. 2005. Pengaruh kepuasan kerja terhadap kinerja karyawan dan efektivitas organisasi. Jurnal Ekonomi Management Fakultas Ekonomi, Universitas Kristen Petra.

Sripirabaa B, Krishnaveni R. .2009. Performance management systems in an Indian manufacturing sector (Partnering, monetary incentives and the alignment of organizational goals). Management Research News 2(10): 942-952. http://dx.doi. org/10.1108/01409170910994150

Talbot C. 2010. Theories of Performance. Oxford: Oxford University Press.

Taylor S. 1994. The relationship between sources of new employees and attitude towards the job. The Journal of Social Psychology 134(1):99-111.

Umar H. 2005. Riset Sumber Daya Manusia Dalam Organisasi. Jakarta: PT. Gramedia Pustaka Utama.

Ullman JC. 1966. Employee referrals: prime tool for recruiting workers. Personnel 43: 30-35.

Vroom VH. 1964. Work and Motivation. New York: John Wiley \& Sons.

Van de Walle S. 2009. International comparisons of public sector performance. Public Management Review 8(2): 39-56.

Vanhala S, Stavrou E. 2013. Human resource management practices and the HRMperformance link in public and private sector organizations in three Western societal clusters. Baltic Journal of Management 8(4): 416-437. http://dx.doi.org/10.1108/BJM-12-2012-0115

Yulianti E. 2009. Analisis proses rekrutmen dan seleksi pada kinerja pegawai. Bisnis \& Birokrasi, Jurnal Ilmu Administrasi dan Organisasi 16(3):131139.

Wibowo. 2007. Manajemen Kinerja. Jakarta: PT. Rajagrafindo Persada. 